\title{
Importance of the Effective Strong Ion Difference of an Intravenous Solution in the Treatment of Diarrheic Calves with Naturally Acquired Acidemia and Strong Ion (Metabolic) Acidosis
}

\author{
K.R. Müller, A. Gentile, W. Klee, and P.D. Constable
}

\begin{abstract}
Background: The effect of sodium bicarbonate on acid-base balance in metabolic acidosis is interpreted differently by Henderson-Hasselbalch and strong ion acid-base approaches. Application of the traditional bicarbonate-centric approach indicates that bicarbonate administration corrects the metabolic acidosis by buffering hydrogen ions, whereas strong ion difference theory indicates that the co-administration of the strong cation sodium with a volatile buffer (bicarbonate) corrects the strong ion acidosis by increasing the strong ion difference (SID) in plasma.

Objective: To investigate the relative importance of the effective SID of IV solutions in correcting acidemia in calves with diarrhea.

Animals: Twenty-two Holstein-Friesian calves (4-21 days old) with naturally acquired diarrhea and strong ion (metabolic) acidosis.

Methods: Calves were randomly assigned to IV treatment with a solution of sodium bicarbonate (1.4\%) or sodium gluconate $(3.26 \%)$. Fluids were administered over 4 hours and the effect on acid-base balance was determined.

Results: Calves suffered from acidemia owing to moderate to strong ion acidosis arising from hyponatremia and hyperD-lactatemia. Sodium bicarbonate infusion was effective in correcting the strong ion acidosis. In contrast, sodium gluconate infusion did not change blood $\mathrm{pH}$, presumably because the strong anion gluconate was minimally metabolized.

Conclusions: A solution containing a high effective SID (sodium bicarbonate) is much more effective in alkalinizing diarrheic calves with strong ion acidosis than a solution with a low effective SID (sodium gluconate). Sodium gluconate is ineffective in correcting acidemia, which can be explained using traditional acid-base theory but requires a new parameter, effective SID, to be understood using the strong ion approach.
\end{abstract}

Key words: Calf diarrhea; Sodium bicarbonate; Sodium gluconate; Strong ion difference.

$\mathbf{T}$ he Henderson-Hasselbalch equation ${ }^{1,2}$ has been used for almost 100 years to characterize the acidbase status of critically ill humans and animals. Application of the Henderson-Hasselbalch equation uses $\mathrm{pH}$ as an overall index of acid-base status, the partial pressure of carbon dioxide $\left(p \mathrm{CO}_{2}\right)$ as an index of the respiratory component of acid-base balance, and either the bicarbonate concentration $\left(\mathrm{CHCO}_{3}{ }^{-}\right)$or extracellular base excess $\left(\mathrm{BE}_{(\mathrm{ecf})}\right)$ as an index of the metabolic or nonrespiratory component of acid-base balance. ${ }^{3,4}$ The Henderson-Hasselbalch approach quantifies the unmeasured anion concentration by calculating the anion gap (AG) from the measured values for the concentrations of sodium, potassium, and chloride in plasma or serum and the calculated value for $\mathrm{CHCO}_{3}{ }^{-3-7}$

Peter Stewart developed a quantitative physicochemical approach to the clinical assessment of acid-base balance from 1978 to $1983,{ }^{8-10}$ and his physicochemical approach was simplified by Constable in $1997 .{ }^{11}$

From the Clinic for Ruminants with Ambulatory and Herd Health Services, Ludwig Maximilian University, Munich, Germany (Müller, Klee); Department of Veterinary Medical Sciences, University of Bologna, Bologna, Italy (Gentile); and Department of Veterinary Clinical Sciences, Purdue University, West Lafayette, IN (Constable). Contents of this article are part of the thesis of the corresponding author.

Corresponding author: Dr. Kristina Müller, Clinic for Ruminants, Sonnenstr. 16, D-85764 Oberschleißheim, Germany; e-mail: KristinaMueller23@gmx.de.

Submitted June 28, 2011; Revised January 14, 2012; Accepted February 21, 2012.

Copyright $(\mathcal{C} 2012$ by the American College of Veterinary Internal Medicine

$10.1111 / j .1939-1676.2012 .00917 . x$

\begin{tabular}{ll} 
Abbreviations: \\
$\mathrm{AG}$ & anion gap \\
$\mathrm{Alb}$ & albumin \\
$A_{\mathrm{tot}}$ & total plasma concentration of nonvolatile weak acids \\
$\mathrm{BE}$ & base excess \\
$\mathrm{mEq}$ & milliequivalent \\
$p \mathrm{CO}_{2}$ & partial carbon dioxide pressure \\
$P$ & $P$-value \\
$\mathrm{SID}$ & strong ion difference \\
$\mathrm{SIG}$ & strong ion gap \\
$\mathrm{TP}$ & total protein \\
\hline
\end{tabular}

Stewart criticized the traditional HendersonHasselbalch model as being too simple and incomplete, especially with regard to metabolic acid-base disturbances. ${ }^{8-10}$ With respect to dissociation equilibria, electroneutrality, and conservation of mass, Stewart's strong ion and Constable's simplified strong ion approaches state that 3 independent variables, $p \mathrm{CO}_{2}$, strong ion difference (SID), and total weak acid concentration $\left(A_{\mathrm{tot}}\right)$, directly determine the dependent variables $\mathrm{pH}$ and $\mathrm{CHCO}_{3}{ }^{-} \cdot{ }^{10,11}$ Strong ions dissociate completely at physiologic $\mathrm{pH}$ and can be subdivided into strong cations $\left(\mathrm{Na}^{+}, \mathrm{K}^{+}, \mathrm{Ca}^{2+}, \mathrm{Mg}^{2+}\right)$ or strong anions (principally $\mathrm{Cl}^{-}$, L-lactate, D-lactate, uremic anions, and ketoacids in cattle). ${ }^{11}$ The strong ion charge difference ( $\Sigma$ strong cation charge $-\Sigma$ strong anion charge) generates a positive value for SID, which is counterbalanced by the negative charges residing on bicarbonate, albumin, globulin, and phosphate. ${ }^{10,11}$ The simplified strong ion approach quantifies the unmeasured strong ion equation by calculating 
the strong ion gap (SIG) from measured values for the plasma or serum concentrations of strong cations and strong anions, the total protein or albumin concentration, and experimentally determined values for $A_{\text {tot }}$ and $\mathrm{pKa}$ in calf plasma., 5,12

Some authors state that in fact the Stewart concept is not completely separate from traditional acid-base concepts, but can rather be seen as an advancement of them. Descriptive indices (BE, Henderson-Hasselbalch equation) are useful for describing and classifying acid-base disorders, whereas quantitative indices (SID, $\left.A_{\text {tot }}\right)$ are more useful for quantifying and explaining these disorders. ${ }^{13}$

Although, the strong ion and simplified strong ion approaches have been criticized, ${ }^{14,15}$ several research groups have investigated quantitative acid-base analysis in domestic animals and concluded that the strong ion approach provided a more comprehensive evaluation of acid-base balance than application of the traditional Henderson-Hasselbalch equation. ${ }^{7,16-21}$ A key question remains to be answered: does application of strong ion theory improve our ability to understand the mechanisms of acid-base equilibrium in vivo and treat acid-base disturbances?

Acid-base disturbances occur commonly in diarrheic calves. The majority of calves have a metabolic acidosis that was traditionally attributed to excessive losses of electrolytes, bicarbonate, and free water in diarrheic feces and decreased renal blood flow that minimized homeostatic adjustments. ${ }^{22}$ As early as 1990 it was recognized that the causes of acidemia in diarrheic calves were incompletely understood. ${ }^{23}$ Nappert, Naylor, and colleagues speculated in 1997 that increased production of organic acids in the gut contributed to the metabolic acidosis and acidemia ${ }^{24}$ and the first reports of hyper-D-lactatemia in sick calves were published the same year in France ${ }^{25}$ and in $1998 .^{26}$ Studies by Naylor and colleagues in Canada ${ }^{27-30}$ and related studies by Lorenz, Gentile, Klee, and colleagues in Europe ${ }^{31-34}$ showed that metabolic acidosis in diarrheic calves frequently resulted from hyper-D-lactatemia because of decreased absorption of substrate with subsequent formation of D-lactate in the gastrointestinal tract. A 2005 study that applied SID theory identified hyponatremia to be an important contributing factor to metabolic acidosis in diarrheic calves, with hyponatremia and hyper-D-lactatemia decreasing SID and thereby inducing a strong ion acidosis. ${ }^{7}$ The same study identified that free water loss and dehydration contributed to the acidemia by increasing serum total protein concentration and consequently the value for $A_{\text {tot. }}{ }^{7}$

Intravenous administration of sodium bicarbonate $(1.3 \%$ or $1.4 \%$ solution) has long been regarded as the therapy of choice in the treatment of diarrheic calves with metabolic acidosis..$^{22,35-37}$ It is of clinical interest that the mechanism of the effect of sodium bicarbonate administration on acid-base balance is interpreted differently by the 2 acid-base models. According to the traditional Henderson-Hasselbalch approach, the administered bicarbonate corrects the metabolic acidosis by buffering hydrogen ions in the extracellular and intracellular compartments, ${ }^{38,39}$ whereas the SID approach indicates that the high effective SID of sodium bicarbonate corrects the strong ion acidosis by increasing the independent variable SID. ${ }^{40-44}$ The effective SID $\left(\mathrm{SID}_{\mathrm{e}}\right)$ of a solution is the difference in charge between the sum of strong (non-metabolizable or fixed) cations such as $\mathrm{Na}^{+}, \mathrm{K}^{+}, \mathrm{Ca}^{2+}$, and $\mathrm{Mg}^{2+}$, and the sum of strong (nonmetabolizable or fixed) anions such as chloride and gluconate. ${ }^{37}$ For example, $0.9 \% \mathrm{NaCl}, 7.2 \% \mathrm{NaCl}$, Ringers solution, and $5 \%$ dextrose solution have an effective SID of $0 \mathrm{mEq} / \mathrm{L}$ and therefore have a net acidifying effect when large volumes are rapidly administered IV.$^{40-42}$ In contrast, $1.4 \% \mathrm{NaHCO}_{3}$ and $8.4 \% \mathrm{NaHCO}_{3}$ have effective SID values of 167 and $1,000 \mathrm{mEq} / \mathrm{L}$, respectively. The importance of effective SID in the alkalinizing ability of an orally administered electrolyte solution was first identified by Staempfli et al in $1996^{45}$ and the concept was extended to characterize the alkalinizing ability of IV fluids in $2003 .{ }^{37}$ The effective SID is not equivalent to bicarbonate because sodium formate is alkalinizing. ${ }^{32}$ The strong ion formate is metabolized primarily to $\mathrm{CO}_{2}$ (thereby increasing SID), but formate does not appear to be metabolized to $\mathrm{HCO}_{3}{ }^{-46-48}$

Another clinically important issue is whether effective volume expansion by administering an isotonic solution with sodium as the only cation is sufficient to correct the metabolic acidosis in diarrheic calves. Only a few studies have been conducted previously in dehydrated diarrheic calves comparing the alkalinizing effect of different sodium containing salts. ${ }^{35,49,50}$ As a result of those studies, the importance of a high effective SID of the infused solution has been identified as central to successful alkalinization.

The primary aim of this clinical study therefore was to clarify the role of increased bicarbonate load to increased sodium load in the treatment of calves with naturally acquired strong ion (metabolic) acidosis because of diarrhea. We achieved our aim by administering approximately isotonic solutions containing similar sodium loads (sodium bicarbonate, sodium gluconate) but markedly different effective SID values. Sodium gluconate was selected for investigation because gluconate is minimally metabolized in calves, ${ }^{36}$ $\operatorname{dogs}^{51}$, and rats. ${ }^{52}$ Experimental studies in rats indicate that $<15 \%$ of gluconate is metabolized to $\mathrm{CO}_{2}$ within 24 hours, with $60-85 \%$ of the administered gluconate being eliminated in the urine. ${ }^{52}$ The effective SID of an isotonic sodium gluconate solution therefore approximates $0 \mathrm{mEq} / \mathrm{L}$, whereas the effective SID of a $1.4 \%$ sodium bicarbonate solution approximates $167 \mathrm{mEq} /$ L. Sodium gluconate therefore provides an excellent solution to compare the specific effects of bicarbonate administration or sodium administration, and effective SID, on acid-base balance.

\section{Materials and Methods}

The study was carried out in collaboration with the Faculty of Veterinary Medicine - University of Bologna, under the supervision of the local Centralized Veterinary Service for Welfare of 
Experimental Animals and with the approval of the Ethical Review Committee of Animal Experimentation of the University of Bologna.

\section{Animals}

The study was performed using a convenience sample of calves from a collaborating farm in Madonna dell'Oppio, Modena, Italy. Calves were housed in open front shelters with individual pens on straw bedding. Twenty-two Holstein-Friesian calves (14 male, 8 female) were enrolled in the study based on the following criteria: age $\leq 21$ days, neonatal diarrhea (defined as loose or watery feces), strong ion (metabolic) acidosis characterized by an extracellular base excess $\left(\mathrm{BE}_{(\mathrm{ecf})}\right)$ of $\leq-7 \mathrm{mmol} /$ $\mathrm{L}$, and the absence of clinical signs of pneumonia or ruminal acidosis.

\section{Clinical Examination and Collection of Samples}

Calves meeting selection criteria were weighed ${ }^{\mathrm{a}}$ and examined using a standardized protocol. Clinical assessments were carried out by the same person who was not blinded to treatment assignment. The general condition and state of hydration of the calf was assessed using a complex composite-scoring system (general condition: posture, behavior, suckling reflex, palpebral reflex): 4 5 = lively, physiologic; 6-9 = slight lethargy; $10-13=$ moderate lethargy; 14-18 = severe lethargy; state of hydration: (degree of enophthalmus, degree of skin tenting): 2 = physiologic; $3-4=$ slight dehydration; 5-6 = moderate dehydration; 7-8 $=$ severe dehydration.

Heparinized blood samples were drawn anaerobically from the jugular vein into polypropylene syringes ${ }^{\mathrm{b}}$ for analysis of blood gas partial pressures, $\mathrm{pH}$, and serum biochemical variables. The syringes were placed in iced water and acid-base parameters were determined within 10 minutes of collection whereas blood for serum analysis was centrifuged $(5,000 \times g, 10$ minutes $)$ and the serum stored at $-20^{\circ} \mathrm{C}$ until analyzed at the Clinic for Ruminants, Oberschleissheim, Germany. An IV catheter ${ }^{c}$ was placed in an auricular vein.

\section{Treatment}

Calves were randomly assigned (by drawing lots) to be treated with either isotonic sodium bicarbonate solution or sodium gluconate solution. Calves were treated by warmed infusion of a slightly hypertonic solution of sodium bicarbonate $(1.4 \%$, $167 \mathrm{mM})$ or an isotonic solution of sodium gluconate $(3.26 \%$, $149 \mathrm{mM}$ ) over 4 hours.

The volume administered was calculated according to the following equation: volume in $\mathrm{L}=$ (body weight in $\mathrm{kg}) \times(0.6 \mathrm{~L} /$ $\mathrm{kg}) \times\left(\mathrm{BE}_{(\mathrm{ecf})} \mathrm{mmol} / \mathrm{L}\right) \times(\mathrm{L} / \mathrm{mmol}$ of bicarbonate or gluconate $)$ where the factor $(0.6 \times$ body weight $)$ was considered to represent the apparent distribution space for bicarbonate in neonatal calves with dehydration and strong ion acidosis. Intravenous solutions were produced by mixing sodium bicarbonate ${ }^{\mathrm{d}}$ or sodium gluconate ${ }^{\mathrm{e}}$ powder with distilled water ${ }^{\mathrm{f}}$ and warmed to approximately $38^{\circ} \mathrm{C}$.

Jugular venous blood samples were obtained immediately before the beginning of infusion (T0), after 2 hours (T120), and after 4 hours, which corresponded to the end of infusion (T240). Clinical variables examined at the end of infusion (T240) included assessment of general condition and state of hydration. Calves were not permitted access to water, milk, or mineral supplements during the 4-hour treatment phase. After the end of infusion, calves were given additional treatments as deemed necessary by the attending veterinarian, based on the results of blood gas and acid-base analysis.

\section{Laboratory Analyses}

Venous blood $\mathrm{pH}$, partial pressure of carbon dioxide $\left(p \mathrm{CO}_{2}\right)$, serum concentrations of sodium $\left(c \mathrm{Na}^{+}\right)$, chloride $\left(c \mathrm{Cl}^{-}\right)$, potassium $\left(c \mathrm{~K}^{+}\right)$, and calcium $\left(c \mathrm{Ca}^{2+}\right)$ were determined with a point of care instrument ${ }^{\mathrm{g}}$ on the farm and expressed in $\mathrm{mEq} / \mathrm{L}$. Serum concentrations of magnesium $\left(c \mathrm{Mg}^{2+}\right)$, total protein $(c \mathrm{TP})$, and albumin $(c \mathrm{Alb})$ as well as concentrations of $\mathrm{D}$ - and L-lactate were determined using an automatic analyzing system $^{\mathrm{h}}$ at the Clinic for Ruminants, Oberschleissheim, Germany.

\section{Calculations}

Henderson-Hasselbalch Equation and Anion Gap. The Henderson-Hasselbalch equation was used to calculate $c \mathrm{HCO}_{3}{ }^{-}$from the measured values for venous $\mathrm{pH}$ and $\mathrm{pCO}_{2}$ and assigned values for $S$ and $\mathrm{pK}_{1}{ }^{\prime}$ at $37^{\circ} \mathrm{C}$ of $0.0307 \mathrm{mmol}^{\circ} \times \mathrm{L}^{-1} \times \mathrm{mmHg}^{-1}$ and 6.095 , respectively, ${ }^{53}$ whereby

$$
c \mathrm{HCO}_{3}^{-}=S \times p \mathrm{CO}_{2} \times 10^{\left(\mathrm{pH}-\mathrm{pK} 1^{\prime}\right)}
$$

Base excess of extracellular fluid $\left(\mathrm{BE}_{(\mathrm{ecf})}\right.$, in $\left.\mathrm{mmol} / \mathrm{L}\right)$ was calculated from the measured $\mathrm{pH}$ and $p \mathrm{CO}_{2}$, and assigned values for $S$ and $\mathrm{pK}_{1}{ }^{53}$ such that:

$$
\mathrm{BE}_{(\mathrm{ecf})}=S \times p \mathrm{CO}_{2} \times 10^{\left(\mathrm{pH}^{\left.-\mathrm{pK} 1^{\prime}\right)}-24.8+16.2 \times(\mathrm{pH}-7.40)\right.}
$$

The unmeasured anion concentration was estimated by calculating the anion gap (AG) as follows ${ }^{3-6}$ :

$$
\mathrm{AG}=\left(c \mathrm{Na}^{+}+c \mathrm{~K}^{+}\right)-\left(c \mathrm{Cl}^{-}+c \mathrm{HCO}_{3}^{-}\right)
$$

Strong Ion Difference, $A_{\text {tot }}$, and Strong Ion Gap. Measured strong ion difference $\left(\mathrm{SIDm}_{7}\right)$ in $\mathrm{mEq} / \mathrm{L}$ was calculated as follows based on the number of strong ions measured (SIDm, $\mathrm{n}=7$ ) in plasma:

$$
\begin{aligned}
& \operatorname{SIDm}_{7}=\left(\left[c \mathrm{Na}^{+}\right]+\left[c \mathrm{~K}^{+}\right]+\left[c \mathrm{Ca}^{2+}\right]+\left[\mathrm{cMg}^{2+}\right]\right)-\left(\left[c \mathrm{Cl}^{-}\right]\right. \\
& \left.+\left[c \text { D-lactate }{ }^{-}\right]+\left[c \text { L-lactate }^{-}\right]\right)
\end{aligned}
$$

The value for $A_{\text {tot }}$ was calculated from the total protein concentration in serum $(c \mathrm{TP})$ in $\mathrm{g} / \mathrm{L}$ using experimentally determined values for calf plasma, ${ }^{7}$ whereby:

$$
A_{\text {tot }}=0.343 \times c \mathrm{TP}
$$

The SIG was calculated from the measured value for cTP in $\mathrm{g} / \mathrm{L}$ and temperature corrected blood $p \mathrm{CO}_{2}$ and $\mathrm{pH}$ value using the SIG equation for calf plasma as follows?

$$
\begin{aligned}
\mathrm{SIG} & =A_{\mathrm{tot}} /\left(1+10^{(\mathrm{pKa}-\mathrm{pH})}\right)-\mathrm{AG} \\
& =c \mathrm{TP} \times\left[0.343 /\left(1+10^{(7.08-\mathrm{pH})}\right)\right]-\mathrm{AG}
\end{aligned}
$$

The unmeasured strong ion concentration ( $c$ USI) was calculated as follows: 


$$
\mathrm{USI}=\mathrm{SIG}+\left(\left[c \text { D-lactate }{ }^{-}\right]+\left[c \text { L-lactate }{ }^{-}\right]\right)
$$

The effective SID $\left(\mathrm{SID}_{\mathrm{e}}\right)$ was calculated as follows:

$$
\operatorname{SIDm}_{7}+c \mathrm{USI}
$$

Change in Plasma Volume. The change in plasma volume at time $i$ was calculated from the serum $c \mathrm{TP}$ at time $=0$ minutes $\left(c \mathrm{TP}_{0}\right)$ and the serum $c \mathrm{TP}$ at time $i\left(c \mathrm{TP}_{i}\right),{ }^{54}$ whereby:

Percent change in plasma volume $=\left(c \mathrm{TP}_{0}-c \mathrm{TP}_{i}\right) \times 100 / c \mathrm{TP}_{i}$

\section{Statistical Analysis}

Statistical analyses were performed using SPSS for Windows version 16. For the 3 sampling times (T0, T120, and T240), a Mann-Whitney- $U$-test was used to compare variables in both groups. Owing to the small number of animals, results are depicted as medians with 25 th and 75 th percentiles. Because of the large number of potentially correlated variables, differences were classified as significant if $P<.01$.

\section{Results}

All calves survived the study. Calves in the sodium bicarbonate group received mean volumes of $1.72 \pm 0.39 \mathrm{~L}$ of isotonic sodium bicarbonate $(1.4 \%)$ solution whereas calves in the sodium gluconate group received mean volumes of $1.67 \pm 0.51 \mathrm{~L}$ of isotonic sodium gluconate $(3.26 \%)$ solution. The variability in volume administered was attributable to the study design whereby calves were given individual volumes of 1 of the solutions. Infusion of sodium gluconate induced moderate inspiratory stertor in 4 calves. The stertor disappeared after T240.

\section{Clinical Appearance, Hydration Status, and Change in Plasma Volume}

Rectal temperature was unchanged during treatment and was similar for both groups (least squares grand mean, $38.7^{\circ} \mathrm{C}$ ). The general condition of the calves improved in both groups within 4 hours of infusion (Fig 1). Initially, calves had a median clinical score of 8.0 (sodium bicarbonate) and 7.0 (sodium gluconate), respectively, indicating slight lethargy. After the study, calves showed almost normal behavior with median clinical scores of 6.0 in both groups.

The hydration status improved similarly in both groups within 4 hours, decreasing from a median score of 5.0 (sodium bicarbonate) and 6.0 (sodium gluconate), respectively (moderate dehydration), to a score of 3.0 (sodium bicarbonate) and 4.0 (sodium gluconate) (mild dehydration) (Fig 2). Serum creatinine concentration decreased numerically but not significantly in both groups by T240 (Table 1).

Plasma volume increased significantly in both groups within 2 hours (Table 1); surprisingly, the mag-

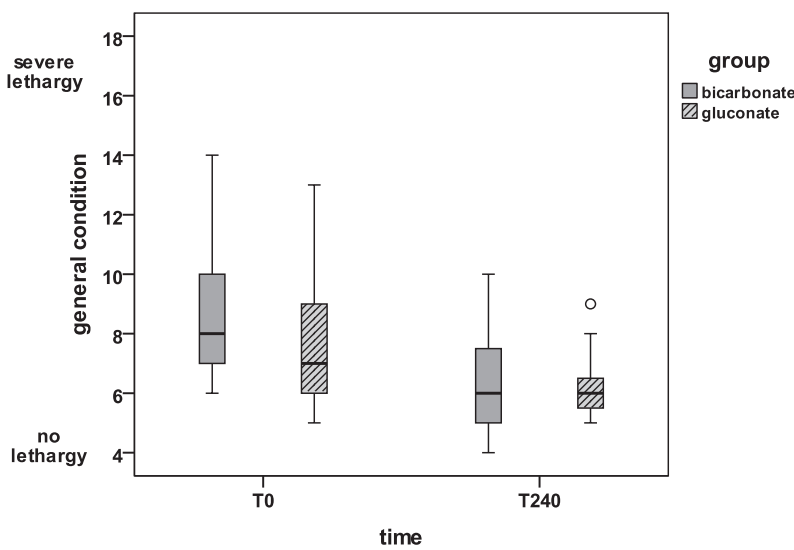

Fig 1. General condition score before (T0) and after (T240) infusion.

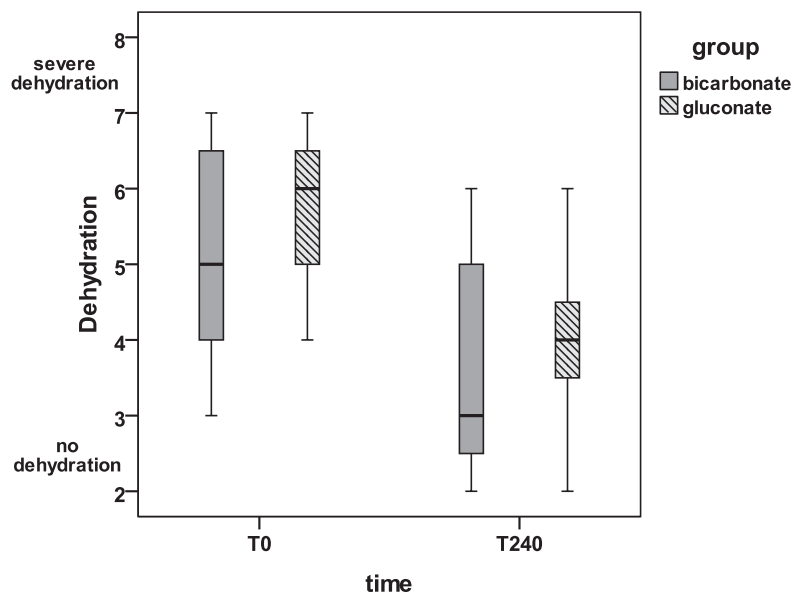

Fig 2. Dehydration score before (T0) and after (T240) infusion.

nitude of the increase was significantly greater for sodium bicarbonate than sodium gluconate at T240.

\section{Serum Electrolyte Concentrations}

Initially, all calves showed moderate hyponatremia (median preprandial sodium concentration: 126$128 \mathrm{mEq} / \mathrm{L}$ ) and although sodium concentrations tended to increase by T240 concentrations remained below the reference interval (Table 1). Serum chloride concentrations were in the reference range at the start of infusion $(104 \mathrm{mEq} / \mathrm{L}$ in the sodium bicarbonate group; $97 \mathrm{mEq} / \mathrm{L}$ in the sodium gluconate group) and decreased slightly in both groups during the study (Table 1).

\section{Henderson-Hasselbalch Assessment of Acid-Base Balance}

Calves suffered from acidemia because of a moderate metabolic acidosis with partial respiratory compensation, as indicated by median values for $\mathrm{BE}_{(\mathrm{ecf})}$ of $-11.3 \mathrm{mmol} / \mathrm{L}$ (sodium bicarbonate) and 
Table 1. Measured blood gas and $\mathrm{pH}$ values, serum electrolyte, total protein, and albumin concentrations, and calculated acid-base parameters before (T0), during (T120) and after (T240) infusion of individual volumes of either sodium bicarbonate (Na-Bic) or sodium gluconate (Na-Gluc). $\mathrm{SIDm}_{7}$ is strong ion difference calculated from 7 strong cations and strong anions. Reference values in square brackets.

\begin{tabular}{|c|c|c|c|c|c|c|c|}
\hline \multirow[b]{2}{*}{ Blood variable } & & \multicolumn{2}{|r|}{ T0 } & \multicolumn{2}{|r|}{$\mathrm{T} 120$} & \multicolumn{2}{|c|}{$\mathrm{T} 240$} \\
\hline & & $\tilde{x}$ & $\mathrm{Q}_{25} / \mathrm{Q}_{75}$ & $\tilde{x}$ & $\mathrm{Q}_{25} / \mathrm{Q}_{75}$ & $\tilde{x}$ & $\mathrm{Q}_{25} / \mathrm{Q}_{75}$ \\
\hline \multicolumn{8}{|l|}{ Henderson-Hasselbalch } \\
\hline$[7.35-7.50]^{59}$ & Na-Gluc & 7.199 & $7.155 / 7.238$ & $7.201^{\mathrm{b}}$ & $7.166 / 7.270$ & $7.217^{\mathrm{b}}$ & $7.189 / 7.287$ \\
\hline$p \mathrm{CO}_{2}(\mathrm{mmHg})$ & $\mathrm{Na}-\mathrm{Bic}$ & 42.6 & $38.9 / 48.1$ & 46.9 & $44.3 / 50.1$ & $48.3^{\mathrm{a}}$ & $45.6 / 53.3$ \\
\hline$[34-45]^{59}$ & Na-Gluc & 45.1 & $44.0 / 51.4$ & 44.2 & $43.6 / 48.5$ & 46.6 & $43.8 / 51.7$ \\
\hline $\mathrm{HCO}_{3}^{-}(\mathrm{mmol} / \mathrm{L})$ & $\mathrm{Na}-\mathrm{Bic}$ & 15.4 & $14.1 / 16.8$ & $22.7^{\mathrm{a}}$ & $20.8 / 24.5$ & $28.0^{\mathrm{a}}$ & $26.2 / 30.5$ \\
\hline$[20-30]^{59}$ & Na-Gluc & 17.2 & $16.6 / 18.4$ & $17.9^{\mathrm{b}}$ & $16.0 / 18.7$ & $19.4^{\mathrm{b}}$ & $17.3 / 20.0$ \\
\hline $\mathrm{BE}_{(\mathrm{ecf})}(\mathrm{mmol} / \mathrm{L})$ & $\mathrm{Na}-\mathrm{Bic}$ & -11.3 & $-13.3 /-10.6$ & $-3.3^{\mathrm{a}}$ & $-4.2 /-1.4$ & $3.7^{\mathrm{a}}$ & $1.4 / 4.9$ \\
\hline$[-2.5-2.5]^{59}$ & Na-Gluc & -10.4 & $-11.5 /-7.8$ & $-9.6^{\mathrm{b}}$ & $-11.3 /-7.2$ & $-7.8^{\mathrm{b}}$ & $-10.6 /-5.8$ \\
\hline Anion gap $(\mathrm{mEq} / \mathrm{L})$ & $\mathrm{Na}-\mathrm{Bic}$ & 19.9 & $16.3 / 23.0$ & 20.5 & $14.2 / 21.5$ & 17.2 & $14.6 / 19.8$ \\
\hline$[14-26]^{59}$ & Na-Gluc & 17.1 & $16.3 / 19.8$ & 21.0 & $19.8 / 28.9$ & $23.2^{\mathrm{b}}$ & $21.7 / 27.6$ \\
\hline \multicolumn{8}{|c|}{ Strong ion difference model } \\
\hline $\operatorname{SIDm}_{7}(\mathrm{mEq} / \mathrm{L})$ & $\mathrm{Na}-\mathrm{Bic}$ & 33.9 & $30.4 / 35.2$ & $38.4^{\mathrm{a}}$ & $36.5 / 40.3$ & $44.6^{\mathrm{a}}$ & $41.4 / 44.9$ \\
\hline$[40 \pm 2]^{7}$ & Na-Gluc & 35.3 & $34.1 / 37.1$ & $42.6^{\mathrm{a}}$ & $40.1 / 43.7$ & $43.3^{\mathrm{a}}$ & $42.0 / 46.2$ \\
\hline $\mathrm{SID}_{\mathrm{e}}(\mathrm{mEq} / \mathrm{l})$ & $\mathrm{Na}-\mathrm{Bic}$ & 30.8 & $29.3 / 33.1$ & $35.5^{\mathrm{a}}$ & $35.5 / 38.8$ & $44.1^{\mathrm{a}}$ & $41.5 / 45.6$ \\
\hline$[40 \pm 2]^{7}$ & $\mathrm{Na}-$ Gluc & 31.0 & $30.2 / 34.2$ & 33.0 & $29.4 / 34.6$ & $32.8^{\mathrm{b}}$ & $31.0 / 34.7$ \\
\hline $\mathrm{A}_{\text {tot }}(\mathrm{mmol} / \mathrm{L})$ & $\mathrm{Na}-\mathrm{Bic}$ & 20.6 & $16.1 / 23.8$ & $18.7^{\mathrm{a}}$ & $15.0 / 21.1$ & $18.4^{\mathrm{a}}$ & $14.6 / 20.4$ \\
\hline$[19.2 \pm 6.1]^{7}$ & Na-Gluc & 18.5 & $17.4 / 20.0$ & $17.2^{\mathrm{a}}$ & $16.4 / 18.2$ & 17.9 & $16.8 / 18.9$ \\
\hline Strong ion gap $(\mathrm{mEq} / \mathrm{L})$ & $\mathrm{Na}-\mathrm{Bic}$ & -8.7 & $-14.3 /-4.9$ & -7.6 & $-11.7 /-2.4$ & $-6.0^{\mathrm{a}}$ & $-7.9 /-3.1$ \\
\hline$[-3-3]^{7}$ & Na-Gluc & -6.2 & $-11.4 /-5.2$ & $-11.2^{\mathrm{a}}$ & $-20,6 /-9.6$ & $-12.1^{\mathrm{ab}}$ & $-20.7 /-11.5$ \\
\hline \multirow{2}{*}{$\begin{array}{l}\text { Unmeasured strong } \\
\text { ions }(\mathrm{mEq} / \mathrm{L})\end{array}$} & $\mathrm{Na}-\mathrm{Bic}$ & -1.8 & $-5.1 /-0.4$ & -2.4 & $-3.3 /+1.4$ & $0.5^{\mathrm{a}}$ & $-1.5 /+2.3$ \\
\hline & $\mathrm{Na}-$ Gluc & -4.7 & $-5.3 /-2.1$ & $-10.4^{\mathrm{ab}}$ & $-13.5 /-4.0$ & $-11.1^{\mathrm{ab}}$ & $-13.9 /-8.3$ \\
\hline \multicolumn{8}{|l|}{ Serum biochemical analysis } \\
\hline \multicolumn{8}{|l|}{ Strong cations } \\
\hline $\mathrm{Na}^{+}(\mathrm{mEq} / \mathrm{L})$ & $\mathrm{Na}-\mathrm{Bic}$ & 126 & $122 / 134$ & 131 & $124 / 133$ & 130 & $126 / 135$ \\
\hline$[132-152]^{59}$ & Na-Gluc & 128 & $120 / 132$ & 129 & $119 / 132$ & 130 & $121 / 134$ \\
\hline $\mathrm{K}^{+}(\mathrm{mEq} / \mathrm{L})$ & $\mathrm{Na}-\mathrm{Bic}$ & 4.6 & $4.1 / 5.2$ & 4.5 & $3.6 / 4.8$ & 3.9 & $3.2 / 4.2$ \\
\hline$[3.9-5.8]^{59}$ & Na-Gluc & 3.8 & $3.4 / 4.5$ & 3.7 & $3.6 / 4.0$ & 3.6 & $3.5 / 4.0$ \\
\hline $\mathrm{Ca}^{2+}(\mathrm{mEq} / \mathrm{L})$ & $\mathrm{Na}-\mathrm{Bic}$ & 2.18 & $1.92 / 2.44$ & 2.06 & $1.80 / 2.24$ & 1.94 & $1.65 / 2.06$ \\
\hline$[1.2-1.6]^{59}$ & Na-Gluc & 2.10 & $1.96 / 2.36$ & 2.18 & $1.95 / 2.24$ & 1.98 & $1.91 / 2.24$ \\
\hline $\mathrm{Mg}^{2+}(\mathrm{mEq} / \mathrm{L})$ & $\mathrm{Na}-\mathrm{Bic}$ & 1.74 & $1.57 / 2.26$ & 1.52 & $1.45 / 1.87$ & 1.54 & $1.40 / 1.89$ \\
\hline$[0.74-1.10]^{59}$ & Na-Gluc & 1.80 & $1.63 / 2.00$ & 1.70 & $1.62 / 1.90$ & 1.64 & $1.59 / 1.82$ \\
\hline \multicolumn{8}{|l|}{ Strong anions } \\
\hline $\mathrm{Cl}^{-}(\mathrm{mmol} / \mathrm{l})$ & $\mathrm{Na}-\mathrm{Bic}$ & 104 & $91 / 101$ & $90^{\mathrm{a}}$ & $86 / 96$ & $86^{\mathrm{a}}$ & $83 / 92$ \\
\hline$[95-110]^{59}$ & Na-Gluc & 97 & $87 / 101$ & $88^{\mathrm{a}}$ & $80 / 94$ & $90^{\mathrm{a}}$ & $79 / 94$ \\
\hline D-Lactate $^{-}(\mathrm{mmol} / \mathrm{l})$ & $\mathrm{Na}-\mathrm{Bic}$ & 3.06 & $1.59 / 7.00$ & 3.75 & $1.81 / 7.27$ & 3.65 & $1.82 / 6.73$ \\
\hline$[0.6-2.2]^{59}$ & Na-Gluc & 2.87 & $0.27 / 5.34$ & 2.76 & $0.14 / 5.26$ & 2.66 & $0.19 / 5.27$ \\
\hline L-Lactate ${ }^{-}(\mathrm{mmol} / \mathrm{l})$ & $\mathrm{Na}-\mathrm{Bic}$ & 0.67 & $0.54 / 0.77$ & 0.79 & $0.56 / 0.98$ & 0.87 & $0.65 / 1.46$ \\
\hline$[0.6-2.2]^{59}$ & $\mathrm{Na}-$ Gluc & 0.84 & $0.52 / 1.27$ & 0.63 & $0.47 / 0.77$ & 0.55 & $0.46 / 0.74$ \\
\hline \multicolumn{8}{|l|}{ Nonvolatile buffer ions } \\
\hline Total protein $(\mathrm{g} / \mathrm{l})$ & $\mathrm{Na}-\mathrm{Bic}$ & 60.1 & $46.9 / 69.5$ & $54.6^{\mathrm{a}}$ & $43.8 / 62.7$ & $53.6^{\mathrm{a}}$ & $42.6 / 59.6$ \\
\hline$[57-81]^{59}$ & $\mathrm{Na}-$ Gluc & 54.0 & $50.7 / 58.3$ & $50.0^{\mathrm{a}}$ & $47.8 / 53.2$ & 52.2 & $49.1 / 55.2$ \\
\hline Albumin $(\mathrm{g} / \mathrm{l})$ & $\mathrm{Na}-\mathrm{Bic}$ & 27.1 & $24.0 / 28.5$ & 24.6 & $22.6 / 25.9$ & 23.8 & $21.6 / 25.1$ \\
\hline$[21-36]^{59}$ & Na-Gluc & 27.6 & $26.8 / 30.5$ & 26.1 & $25.0 / 27.5$ & 26.0 & $25.1 / 27.4$ \\
\hline Phosphorus (mmol/L) & $\mathrm{Na}-\mathrm{Bic}$ & 2.6 & $2.3 / 3.6$ & 2.4 & $2.1 / 2.9$ & 2.2 & $2.1 / 2.8$ \\
\hline$[1.08-2.76]^{59}$ & Na-Gluc & 2.6 & $2.5 / 3.0$ & 2.6 & $2.5 / 2.7$ & 2.6 & $2.5 / 2.7$ \\
\hline Creatinine (umol/L) & $\mathrm{Na}-\mathrm{Bic}$ & 107.8 & $67.0 / 171.1$ & 93.2 & $61.8 / 150.7$ & 92.6 & $57.1 / 136.9$ \\
\hline$[67-175]^{59}$ & Na-Gluc & 116.4 & $90.5 / 144.4$ & 104.7 & $88.5 / 125.5$ & 96.9 & $87.7 / 118.1$ \\
\hline \multirow{2}{*}{$\begin{array}{l}\text { Percent change in plasma } \\
\text { volume }\end{array}$} & $\mathrm{Na}-\mathrm{Bic}$ & 0.0 & $0.0 / 0.0$ & $+11.4^{\mathrm{a}}$ & $8.9 / 19.0$ & $+14.6^{\mathrm{a}}$ & $11.5 / 20.1$ \\
\hline & Na-Gluc & 0.0 & $0.0 / 0.0$ & $+9.0^{\mathrm{a}}$ & $4.0 / 14.7$ & $+7.5^{\mathrm{a}, \mathrm{b}}$ & $4.4 / 11.2$ \\
\hline
\end{tabular}

$\tilde{x}=$ median.

$\mathrm{Q}_{25} / \mathrm{Q}_{75}=25-/ 75$-quartiles

${ }^{\text {a }}$ Significantly different from time $=0$ value within a group

${ }^{\mathrm{b}}$ Significantly different between the 2 groups at the same time $(P \leq 0.0023)$. 
$-10.4 \mathrm{mmol} / \mathrm{L}$ (sodium gluconate), and $p \mathrm{CO}_{2}$ of $43 \mathrm{mmHg}$ (sodium bicarbonate) and $45 \mathrm{mmHg}$ (sodium gluconate) immediately before treatment. Blood $\mathrm{pH}, c \mathrm{HCO}_{3}^{-}$, and $\mathrm{BE}_{\text {(ecf) }}$ were increased at $\mathrm{T} 120$ and T240, and $p \mathrm{CO}_{2}$ was increased at T240 after sodium bicarbonate infusion, at which time the values reached the reference range (Table 1; Fig 3). In marked contrast, infusion of sodium gluconate did not change blood $\mathrm{pH}, p \mathrm{CO}_{2}, c \mathrm{HCO}_{3}{ }^{-}$, and $\mathrm{BE}_{(\text {ecf) }}$ values. Consequently, blood $\mathrm{pH}, \mathrm{CHCO}_{3}{ }^{-}$, and $\mathrm{BE}_{\text {(ecf) }}$ (Fig 3) were significantly different $(P \leq .01)$ at T120 and T240 between the 2 groups. The AG remained constant in calves treated with sodium bicarbonate but was significantly increased in calves treated with sodium gluconate. Collectively, these results indicate that sodium bicarbonate was an effective alkalinizing agent, sodium gluconate was an ineffective alkalizing agent, and the increase in AG indicated that much of the infused gluconate was not metabolized or failed to be eliminated by urinary clearance.

\section{Strong Ion Difference Theory Assessment of Acid-Base Balance}

Calves suffered from acidemia immediately before treatment that was primarily because of strong ion acidosis (decreased median values for $\operatorname{SIDm}_{7}, \mathrm{SID}_{\mathrm{e}}$, and negative values for SIG) and to a lesser extent because of nonvolatile buffer ion acidosis (increased values for $A_{\text {tot }}$; Table 1). The decreases in $\mathrm{SIDm}_{7}$ and $\mathrm{SID}_{\mathrm{e}}$ primarily were because of hyponatremia and increased concentration of the strong ion D-lactate. Blood $\mathrm{pH}, \mathrm{SIDm}_{7}$ (Fig 4), and $\mathrm{SID}_{\mathrm{e}}$ were increased, SIG was more positive (Fig 5), and $A_{\text {tot }}$ was decreased at T120 and T240 after sodium bicarbonate infusion at which time the values reached the reference range (Table 1; Fig 6). In marked contrast, infusion of sodium gluconate did not change blood $\mathrm{pH}$ and effective SID, despite an increase in $\mathrm{SIDm}_{7}$ and decrease in $A_{\text {tot }}$ after treatment (Fig 6). The SIG was significantly more negative after sodium gluconate administration. Also in this model, sodium bicarbonate was an effec-

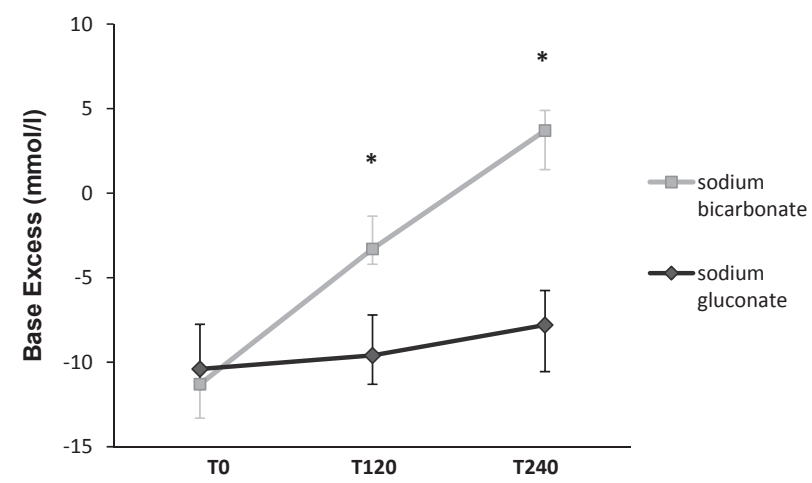

Fig 3. Medians and 25 th and 75 th quartiles of base excess values before (T0), during (T120), and after (T240) infusion. * = significant difference between the 2 groups at the same time $(P \leq .0023)$. tive alkalinizing agent, sodium gluconate was an ineffective alkalinizing agent, and the increase in SIG indicated that much of the infused gluconate was not metabolized or failed to be eliminated by urinary clearance.

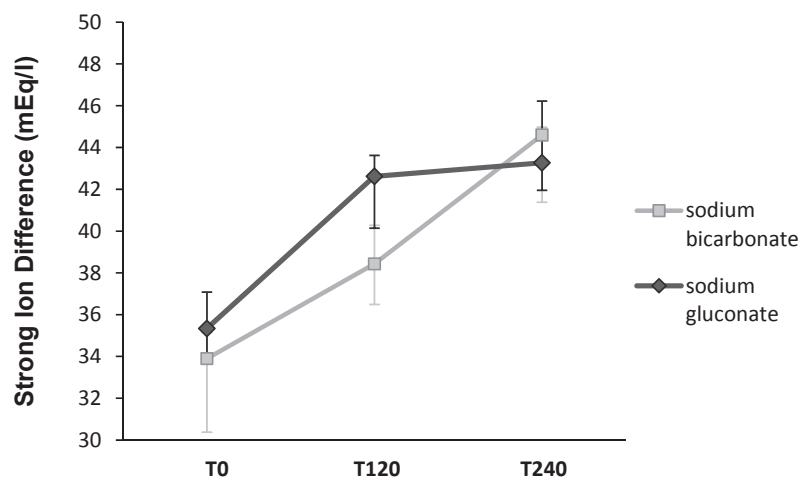

Fig 4. Medians and 25th and 75th quartiles of strong ion difference $\left(\mathrm{SIDm}_{7}\right)$ values before (T0), during (T120) and, after (T240) infusion.

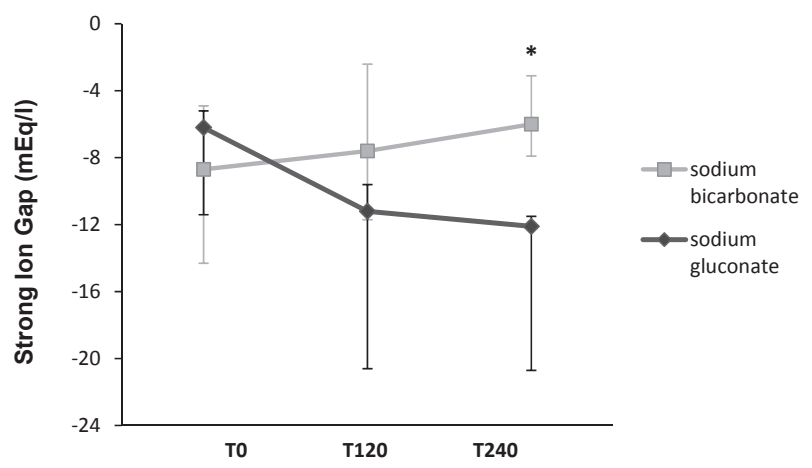

Fig 5. Medians and 25th and 75th quartiles of strong ion gap values before (T0), during (T120), and after (T240) infusion. * = significant difference between the 2 groups at the same time $(P \leq .0023)$.

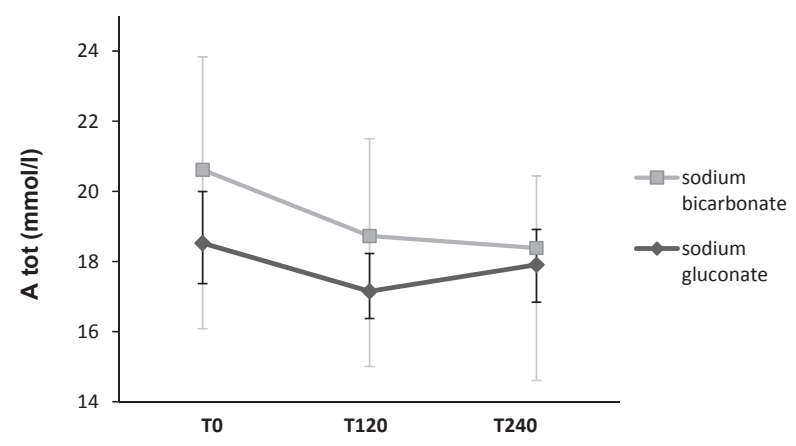

Fig 6. Medians and 25 th and 75 th quartiles of $A_{\text {tot }}$ values before (T0), during (T120), and after (T240) infusion. 


\section{Discussion}

The results of this study provide clear evidence of the central role that the effective SID of the infused solution exerts on acid base status. Specifically, infusion of an isotonic solution with an effective SID of approximately $0 \mathrm{mEq} / \mathrm{L}$ (such as $3.26 \%$ sodium gluconate, this study) or $0.9 \% \mathrm{NaCl}^{23}$ has minimal effect on blood $\mathrm{pH}$, whereas infusion of a slightly hypertonic solution with a high effective SID of $167 \mathrm{mEq} / \mathrm{L}$ ( $1.4 \%$ sodium bicarbonate) is an effective alkalinizing agent. This finding confirms the previous finding by Naylor and Forsyth in $1986^{36}$ that sodium gluconate is not an effective alkalinizing agent in neonatal calves and emphasizes the important role that the effective SID of the infused solution has on altering acid-base status. ${ }^{7,37,40-42}$

Moderate to severe hyponatremia $(127 \mathrm{mmol} / \mathrm{L})$ was observed in diarrheic calves, presumably owing to excessive sodium loss in the small intestine and decreased milk intake. ${ }^{22,55}$ The important role that hyponatremia plays in producing acidemia and strong ion (metabolic) acidosis in diarrheic calves was first identified by application of strong ion difference theory. ${ }^{7}$ The clinical importance of hyponatremia was overlooked before publication of the 2005 study because the Henderson-Hasselbalch approach to acidbase equilibria is more descriptive than mechanistic, ${ }^{11}$ and may fail to identify the mechanism for an acidbase disturbance., ${ }^{3,4,7,11}$ The clinical importance of hyponatremia in driving the strong ion acidosis in calves with diarrhea has provided strong support for the administration of hypertonic solutions of sodium bicarbonate ${ }^{56,57}$ as part of the initial treatment of diarrheic calves. Moreover, the common occurrence of hyponatremia in untreated calves strongly suggests that $1.4 \%$ sodium bicarbonate solutions are more appropriate for the routine treatment of affected calves than $1.3 \%$ sodium bicarbonate solutions.

Changes in total protein concentration of plasma were minor in the calves of this study and consequently had minimal effects on acid-base balance. This observation is in contrast to a previous study in diarrheic calves in which affected animals were more dehydrated and consequently had increased concentrations of total protein and albumin in serum. ${ }^{7}$ Nevertheless, the small decrease in serum $c \mathrm{TP}$ that occurs after IV infusion of $1.4 \%$ sodium bicarbonate or $3.26 \%$ sodium gluconate would be expected to exert a mild alkalinizing effect that probably offsets the acidifying effect of infusing sodium gluconate, which has an effective SID of approximately $0 \mathrm{mEq} / \mathrm{L} .^{37,40-42}$

A clinically important weakness of strong ion difference theory is the difficulty in obtaining an accurate estimate off SID. ${ }^{3,4,7,11}$ When SID is calculated from measured strong cation and anion concentrations, it is preferable to call the factor measured SID (SIDm) to emphasize that it is measured and therefore an estimated value for SID and not necessarily an accurate value. Moreover, it is helpful to indicate the number of strong cations and strong anions used to provide the estimate for $\operatorname{SID},{ }^{7,11,12}$ hence, the use of the term $\mathrm{SIDm}_{7}$ in the study reported here. $\mathrm{SIDm}_{7}$ was low initially in both groups $(34-35 \mathrm{mEq} / \mathrm{L})$, compared to an estimated SID value of $44 \mathrm{mEq} / \mathrm{L}$ (Table 1) in healthy calves. ${ }^{7}$ Infusion of sodium bicarbonate and sodium gluconate increased $\mathrm{SIDm}_{7}$ to approximately 43$45 \mathrm{mEq} / \mathrm{L}$, but, the calculated value for $\mathrm{SIDm}_{7}$ in calves treated with sodium gluconate failed to include the quantitatively important effect of gluconate on the true value for SID. This highlights the importance of calculating SIG when applying strong ion difference theory. This is because the SIG quantifies the net strong ion charge in plasma and alerts the clinician to the presence of unmeasured strong anions (such as gluconate), or much less commonly, strong cations. Indeed, calculation of the effective SID showed that infusion of sodium gluconate did not alter effective SID values, whereas sodium bicarbonate produced an increase in $\mathrm{SID}_{\mathrm{e}}$ to $44 \mathrm{mEq} / \mathrm{L}$.

Both AG and SIG were able to identify the presence of increased concentrations of an unmeasured anion (AG) or strong ion (SIG) after infusion of 3.26\% sodium gluconate (Fig 5). Although not verified in the study reported here, it is believed that SIG provides a more accurate estimate of the unmeasured strong anion concentration than AG because SIG accounts for concurrent changes in serum total protein concentration; the latter changes markedly in critically ill patients treated with IV fluids. ${ }^{3-5}$ Moreover, changes in SIG over time provide a quantitative measure of the rate of metabolism of an unmeasured strong anion such as gluconate. Other investigators reported high concentrations of unmeasured strong anions after infusion of a commercially available solution containing acetate and gluconate in patients with cardiopulmonary bypass, ${ }^{58}$ presumably because of the presence of unmetabolized gluconate. Because gluconate is an important component of commercially available solutions such as $23 \%$ calcium gluconate and acetated Ringer's solution, the slow metabolism of gluconate is clinically important because the sustained presence of a strong anion will result in hypochloremia, and in some cases, strong ion acidosis.

The SID approach to acid-base equilibria posits that the high effective SID of a $1.4 \%$ sodium bicarbonate solution corrects the strong ion acidosis by increasing the independent variable SID. ${ }^{37,40-43}$ In the SID context, sodium gluconate failed to correct the strong ion acidosis because the effective SID of the infused solution was approximately $0 \mathrm{mEq} / \mathrm{L}$, which will tend to have a mild acidifying effect. The traditional HendersonHasselbalch approach also provides an explanation for the observed results in that $1.4 \%$ sodium bicarbonate solution corrects the metabolic acidosis by buffering protons in the extracellular and intracellular compartments, producing water and $\mathrm{CO}_{2},{ }^{38,39}$ such that $\mathrm{HCO}_{3}{ }^{-}+\mathrm{H}^{+} \leftrightarrow \mathrm{CO}_{2}+\mathrm{H}_{2} \mathrm{O}$. In this study, $p \mathrm{CO}_{2}$ was significantly increased at $\mathrm{T} 240$ after sodium bicarbonate infusion whereas infusion of sodium gluconate produced little change in $p \mathrm{CO}_{2}$ (Table 1). The Henderson-Hasselbalch approach to acid-base equilibria 
posits that sodium gluconate failed to correct the metabolic acidosis because it was not metabolized to bicarbonate and therefore was unable to buffer protons in the extracellular and intracellular compartments. Previous studies demonstrated that gluconate is poorly metabolized in healthy and acidotic calves. ${ }^{36,38}$ Infusion of sodium gluconate produced little change in $\mathrm{pH}$ or base excess with time and blood gluconate concentrations increased to high concentrations as the gluconate accumulated in blood. Other metabolizable bases such as acetate or L-lactate were rapidly metabolized and the alkalinizing effect had a similar time course to that seen with bicarbonate. ${ }^{36}$

The general condition and degree of hydration of the calves were assessed by a clinical score. Our finding that the general condition of the calves entering the study was only slightly abnormal was attributed to the close observation and daily care by a veterinarian. Owing to this close monitoring, calves entered the study immediately after fulfilling the selection criteria and responded well to treatment during the 4 hours of the study and immediately after calves were infused with $3.26 \%$ sodium gluconate. A $1.4 \%$ sodium bicarbonate solution expanded the plasma volume to a greater extent than did $3.26 \%$ sodium gluconate solution. This was most likely owing to the higher sodium load and tonicity of the infused solution in calves treated with $1.4 \%$ sodium bicarbonate (sodium concentration $=167 \mathrm{mmol} / \mathrm{L}$ ) versus $3.26 \%$ sodium gluconate (sodium concentration $=149 \mathrm{mmol} / \mathrm{L}$ ).

Infusion of sodium gluconate induced moderate inspiratory stertor in 4 calves, which probably occurred owing to slight swelling of mucous membranes in the upper airways. The cause for this sign is unknown. Because the infused solutions were prepared individually with intervals of days or weeks, and other calves receiving the sodium gluconate solution did not show stertor, contamination of the infused solutions seems unlikely. The stertor disappeared shortly after infusion (after approximately 30 minutes).

In other studies, the plasma D-lactate concentration decreased exponentially with time $e^{30,32}$ whereas in this study $c$ D-lactate did not decrease significantly in both groups within 4 hours of infusion. Possibly, a mean volume of $1.7 \mathrm{~L}$ of infused solution was not enough to reestablish urine production and therefore excretion of D-lactate or perhaps exogenous production of D-lactate continued in the gastrointestinal tract of the diarrheic calves during the study, with intestinal absorption rates approximating the clearance rate from plasma.

In conclusion, results of this study support the application of strong ion difference theory to acid-base disorders. The results confirm from the previous findings $^{7}$ that hyponatremia and hyper-D-lactatemia play important and primary roles in the development of acidemia and strong ion (metabolic) acidosis in diarrheic calves. Moreover, application of strong ion theory provides an easily understood explanation for the important role that the effective SID of administered fluids plays in altering acid-base balance.

\section{Footnotes}

a Analog weigh scales, not specified

${ }^{\mathrm{b}}$ BD Discardit ${ }^{\mathrm{TM}}$ II, $2 \mathrm{~mL}$, Becton, Dickinson and Company, Franklin Lakes, NJ

${ }^{c}$ Vasuflo T, G20, Dispomed Witt oHG, Gelnhausen, Germany

${ }^{\mathrm{d}}$ Sodio Bicarbonato E500 Polvere, Polichimica S.R.L., Bologna, Italy

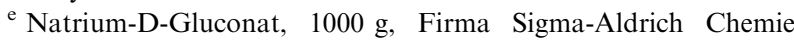
$\mathrm{GmbH}$, Steinheim, Germany

${ }^{\mathrm{f}}$ Acqua per Preparazioni iniettabili sterile apirogena, $2000 \mathrm{~mL}$, Firma ACME S.R.L., Cavriago, Italy

g ABL 700, Radiometer, Copenhagen, Denmark

${ }^{\text {h }}$ Hitachi Automatic Analyzer 912 E, Roche Diagnostics, Mannheim, Germany

\section{References}

1. Henderson LJ. The theory of neutrality regulation in the animal organism. Am J Physiol 1908;21:427-428.

2. Hasselbalch KA. Die Berechnung der Wasserstoffzahl des Blutes aus der freien und gebundenen Kohlensäure desselben, und die Sauerstoffbindung des Blutes als Funktion der Wasserstoffzahl. Biochem Z 1916;78:112-144.

3. Constable PD. Clinical assessment of acid-base status. Strong ion difference theory. Vet Clin North Am Food Anim Pract 1999;15:447-471.

4. Constable PD. Clinical assessment of acid-base status: Comparison of the Henderson-Hasselbalch and strong-ion approaches. Vet Clin Pathol 2000;29:115-128.

5. Constable PD, Streeter RK, Koenig GR, et al. Determinants and utility of the anion gap in predicting hyperlactatemia in cattle. J Vet Intern Med 1997;11:71-79.

6. Constable PD, Hinchcliff KW, Muir WW. Comparison of anion gap and strong ion gap as predictors of unmeasured strong ion concentration in plasma and serum from horses. Am J Vet Res 1998;59:881-887.

7. Constable PD, Stämpfli HR, Navetat H, et al. Use of a quantitative strong ion approach to determine the mechanism for acid-base abnormalities in sick calves with or without diarrhea. J Vet Intern Med 2005;19:581-589.

8. Stewart PA. Independent and dependent variables of acidbase control. Resp Physiol 1978;33:9-26.

9. Stewart PA. How to approach acid base. 1981. Available at: http://www.AcidBase.org, accessed March 14, 2012.

10. Stewart PA. Modern quantitative acid-base chemistry. Can J Physiol Pharmacol 1983;61:1444-1461.

11. Constable PD. A simplified strong ion model for acid base equilibria: Application to horse plasma. J Appl Physiol 1997;83:297-311.

12. Constable PD. Calculation of variables describing plasma nonvolatile weak acids for use in the strong ion approach to acid-base balance in cattle. Am J Vet Res 2002;63:482-490.

13. Kellum JA. Clinical review: Reunification of acid-base physiology. Crit Care 2005;9:500-507.

14. Siggaard-Andersen O, Fogh-Andersen N. Base excess or buffer base (strong ion difference) as measure of a non-respiratory acid-base disturbance. Acta Anaesth Scand Suppl 1995; 107:123-128.

15. Kurtz I, Kraut J, Ornelian V, Nguyen MK. Acid-base analysis: A critique of the Stewart and bicarbonate-centered approaches. Am J Physiol-Renal Physiol 2008;294:F1009F1031. 
16. de Morais H, Constable PD. Strong ion approach to acidbase disorders. In: DiBartola SP, ed. Fluid, Electrolyte, and Acid-Base Disorders in Small Animal Practice. 3rd ed. Philadelphia, PA: W.B. Saunders Company; 2006:310-321.

17. Siegling-Vlitakis C, Kohn B, Kellermeier C, et al. Qualification of the Stewart variables for the assessment of the acidbase status in healthy dogs and dogs with different diseases. Berl Münch Tierärztl Wschr 2007;120:148-155.

18. Bachmann L, Homeier T, Arlt S, et al. Influence of different oral rehydration solutions on abomasal conditions and the acidbase status of suckling calves. J Dairy Sci 2009;92:1649-1659.

19. Elkhair N, Siegling-Vlitakis C, Radtke E, et al. Agedependent response of the acid-base parameters (Henderson-Hasselbalch, Stewart) in healthy calves with experimentally induced metabolic acidosis. Berl Münch Tierärztl Wschr 2009;122:63-69.

20. Reinhold P, Hartmann H, Constable PD. Characterization of acid-base abnormalities in pigs experimentally infected with Chlamydia suis. Vet J 2010;184:212-218.

21. Viu J, Jose-Cunilleras E, Armengou L, et al. Acid-base imbalances during a $120 \mathrm{~km}$ endurance race compared by traditional and simplified strong ion difference methods. Equine Vet $\mathbf{J}$ Suppl 2010;42Suppl 38:76-82. evj_213 76.82

22. Berchtold J. Intravenous fluid therapy of calves. Vet Clin North Am Food Anim Pract 1999;15:505-531.

23. Naylor JM. Oral fluid therapy in neonatal ruminants and swine. Vet Clin North Am Food Anim Pract 1990;6:51-67.

24. Nappert G, Zello GA, Naylor JM. Oral rehydration therapy for diarrheic calves. Compend Contin Educ Pract Vet (Food Animal Practice) 1997;19:S181-S190.

25. Navetat $H$, Biron $P$, Contrepois $M$, et al. Les gastroentérites paralysantes: Maladie ou syndrome? Bull Acad Vet de France 1997;70:327-336.

26. Schelcher F, Marcillaud S, Braun JP, et al. Metabolic acidosis without dehydration and no or minimal diarrhoea in suckler calves is caused by hyper D-lactatemia. Proceedings of the World Buiatric Congress, Sydney, Australia, 1998;371-374.

27. Omole OO, Nappert G, Naylor JM, Zello GA. Both Land D-lactate contribute to metabolic acidosis in diarrheic calves. J Nutr 2001;131:2128-2131.

28. Ewaschuk JB, Naylor JM, Zello GA. Anion gap correlates with serum D- and DL-lactate concentrations in diarrheic calves. J Vet Intern Med 2003;17:940-942.

29. Ewaschuk JB, Naylor JM, Palmer R, et al. D-lactate production and excretion in diarrheic calves. $\mathbf{J}$ Vet Intern Med 2004; 18:744-747.

30. Abeysekara S, Naylor JM, Wassef AW, et al. D-lactic acid-induced neurotoxicity in a calf model. Am J Physiol Endocrinol Metab 2007;293:E558-E565.

31. Gentile A, Sconza S, Lorenz I, et al. D-lactic acidosis in calves as a consequence of experimentally induced ruminal acidosis. J Vet Med A Physiol Pathol Clin Med 2004;51:64-70.

32. Lorenz I, Gentile A, Klee W. Investigations of D-lactate metabolism and the clinical signs of D-lactataemia in calves. Vet Rec 2005; 156:412-415.

33. Gentile A, Lorenz I, Sconza S, Klee W. Experimentally induced systemic hyperchloremic acidosis in calves. J Vet Intern Med 2008;22:190-195.

34. Lorenz I. D-lactic acidosis in calves. Vet J 2009;179:197203.

35. Kasari T, Naylor J. Clinical evaluation of sodium bicarbonate, sodium L-lactate and sodium acetate for the treatment of acidosis in diarrheic calves. J Am Vet Med Assoc 1985;187:392397.

36. Naylor J, Forsyth G. The alkalinizing effects of metabolizable bases in the healthy calf. Can J Vet Res 1986;50:509-516.

37. Constable PD. Fluids and electrolytes. In: Brumbaugh GW, guest ed. Clinical Pharmacology. Vet Clin North Am Food
Anim Pract. Philadelphia, PA: W.B. Saunders Company; 2003;19:1-40.

38. Hartsfield SM. Sodium bicarbonate and bicarbonate precursors for treatment of metabolic acidosis. J Am Vet Med Assoc 1981;179:914-916.

39. Robergs RA, Ghiasvand F, Parker D. Biochemistry of exercise-induced metabolic acidosis. Am J Physiol Regul Integr Comp Physiol 2004;287:R502-R516.

40. Constable PD. Hyperchloremic acidosis: The classic example of strong ion acidosis. Anesth Analg 2003;96:919-922.

41. Constable PD. In response: Letters to the editor. Anesth Analg 2004;98:271-272.

42. Constable PD. Iatrogenic hyperchloremic acidosis due to large volume fluid administration: Mechanism, diagnosis, and management. Int J Intens Care 2005;12:111-122.

43. Constable PD. Strong ion difference theory: A revolutionary approach to the diagnosis and treatment of acid-base abnormalities in cattle. Hungarian Vet J 2008;130 Suppl 1. Keynote lectures:28-33.

44. Deetjen P, Lichtwarck-Aschoff M. Säure-Base-Haushalt aus der Perspektive von P. Stewart. Anaesthesist 2007;56:11851199.

45. Stämpfli HR, Pringle JH, Lumsden JH, et al. Experimental evaluation of a novel oral electrolyte solution in the treatment of natural occurring neonatal calf diarrhoea. Proceedings of the XIXth World Buaitrics Congress, Edinburgh, Scotland, U.K, 1996, 98-101, British Cattle Association, Edinburgh, Scotland, UK, 1996

46. Constable PD, Gruenberg W, Carstensen L. Comparative effects of two oral rehydration solutions on milk clotting, abomasal luminal $\mathrm{pH}$, and abomasal emptying rate in suckling calves. $\mathbf{J}$ Dairy Sci 2009;92:296-312.

47. Annison EF, White RR. Formate metabolism in sheep. Biochem J 1962;84:552-557.

48. Hanzlik RP, Fowler SC, Eells JT. Absorption and elimination of formate following oral administration of calcium formate in female human subjects. Drug Metab Dispos 2005;33:282-286.

49. Berchtold JF. Investigation on the diagnosis and treatment of systemic acidosis in calves. Diss. Med. Vet., Free University of Berlin; 1998.

50. Sen I, Altunok V, Ok M, et al. Efficacy of oral rehydration therapy solutions containing sodium bicarbonate or sodium acetate for treatment of calves with naturally acquired diarrhea, moderate dehydration, and strong ion acidosis. J Am Vet Med Assoc 2009;234:926-934.

51. Kirkendol P, Starrs J, Gonzalez F. The effects of acetate, lactate, succinate and gluconate on plasma $\mathrm{pH}$ and electrolytes in dogs. Trans Am Soc Artif Intern Organs 1980;26:323-327.

52. Stetten MR, Topper YJ. Pathways from gluconic acid to glucose in vivo. J Biol Chem 1953;203:653-664.

53. CLSI. Blood Gas and pH Analysis and Related Measurements; Approved Guidelines. 2nd edition. CLSI document C46A2. Wayne, PA: Clinical and Laboratory Standards Institute; 2009.

54. van Beaumont W, Greenleaf JE, Juhos L. Disproportional changes in hematocrit, plasma volume, and proteins during exercise and bed rest. J Appl Physiol 1972;33:55-61.

55. Fischer W, Butte R. Vergleichende untersuchungen des elektrolyt- und blutstatus bei gesunden und an enteritis erkrankten kälbern. (1. Mitteilung). Dtsch Tierärztl Wschr 1974;81:567570 .

56. Berchtold JF, Constable PD, Smith GW, et al. Effects of intravenous hyperosmotic sodium bicarbonate on arterial and cerebrospinal fluid acid-base status and cardiovascular function in calves with experimentally induced respiratory and strong ion acidosis. J Vet Intern Med 2005;19:240-251. 
57. Koch A, Kaske M. Clinical efficacy of intravenous hypertonic saline solution or hypertonic bicarbonate solution in the treatment of inappetent calves with neonatal diarrhea. J Vet Intern Med 2008;22:202-211.

58. Liskaser F, Bellomo R, Hayhoe M, et al. Role of pump prime in the etiology and pathogenesis of cardiopulmonary bypass-associated acidosis. Anesthesiology 2000;93:1170-1173.
59. Radostits OM, Gay CC, Hinchcliff KW, Constable PD. Reference laboratory values. Appendix 2. In: Radostits OM, Gay CC, Hinchcliff KW, Constable PD, eds. Veterinary Medicine. A Textbook of the Diseases of Cattle, Horses, Sheep, Pigs and Goats. 10th ed. Philadelphia, PA: W.B. Saunders Company; 2007: 2047-2050. 